\title{
Simultaneous Quantification of Lycopene, $\beta$-Carotene, Retinol and $\alpha$-Tocopherol in Plasma after a Simple Extraction Procedure: Stability Study and Application to Human Volunteers
}

\author{
Mariele F. Charão, ${ }^{a, b}$ Angela M. Moro, ${ }^{a, c}$ Natália Brucker, ${ }^{a, c}$ Rachel P. Bulcãoo, ${ }^{a, c}$ \\ Marília Baierle, ${ }^{a, c}$ Fernando Freitas, ${ }^{a, c}$ Juliano Durgante, ${ }^{a}$ Sabrina Nascimento, ${ }^{a}$ \\ Guilherme B. Bubols, ${ }^{a, c}$ Paulo H. Saldiva, ${ }^{d}$ Denise Bohrer ${ }^{e}$ and Solange C. Garcia ${ }^{*, a, c}$ \\ ${ }^{a}$ Laboratory of Toxicology, Department of Analysis, Federal University of Rio Grande do Sul, \\ 90610-000 Porto Alegre-RS, Brazil \\ ${ }^{b}$ Post-Graduate Program of Pharmacology, Center of Healthy Sciences, \\ Federal University of Santa Maria, 97105-900 Santa Maria-RS, Brazil \\ ${ }^{c}$ Post-Graduate Program in Pharmaceutical Sciences, Federal University of Rio Grande do Sul, \\ 90610-000 Porto Alegre-RS, Brazil \\ ${ }^{d}$ Laboratory of Experimental Air Pollution, Medical School, University of São Paulo, \\ 01246-903 São Paulo-SP, Brazil
}

eDepartment of Chemistry, Federal University of Santa Maria, 97105-900 Santa Maria-RS, Brazil

Um método para quantificação simultânea de licopeno, $\beta$-caroteno, retinol e $\alpha$-tocoferol por cromatografia líquida de alta eficiência (HPLC) com detecção no visível/fluorescente e eluição isocrática foi otimizado e validado. O método consiste de extração líquido-líquido rápida e simples e posterior quantificação do sobrenadante extraído por HPLC. Alíquotas de plasma foram estocadas a $-20^{\circ} \mathrm{C}$ por três meses para estudo da estabilidade. Aplicação metodológica foi realizada em amostras fornecidas por pintores e indivíduos não expostos a tintas $(\mathrm{n}=75)$. O ensaio foi linear para todas as vitaminas analisadas $(r>0,99)$. Precisões intradia e interdia apresentaram coeficiente de variação $(\mathrm{CV})$ menor que $5 \%$. Exatidões variaram de 0,29 a $-5,80 \%$ e recuperações entre 92,73 e $101,97 \%$. Amostras de plasma e sobrenadante extraído foram estáveis por até 60 dias a $-20^{\circ} \mathrm{C}$. Foi demonstrada uma diminuição significativa nas concentrações de licopeno, $\beta$-caroteno e retinol em indivíduos expostos quando comparados com os não-expostos $(p<0,05)$. O método é simples, reprodutível, preciso, exato e sensível, e pode ser utilizado na rotina de laboratórios clínicos.

A method for the simultaneous quantification of lycopene, $\beta$-carotene, retinol and $\alpha$-tocopherol by high-performance liquid chromatography (HPLC) with Vis/fluorescence detection with isocratic elution was optimized and validated. The method consists of a rapid and simple liquid-liquid extraction procedure and a posterior quantification of extracted supernatants by HPLC. Aliquots of plasma were stored at $-20^{\circ} \mathrm{C}$ for three months for stability study. The methodology was applied to samples from painters and individuals not exposed to paints $(n=75)$. The assay was linear for all vitamins $(r>0.99)$. Intra- and inter-run precisions were obtained with coefficient of variation smaller than $5 \%$. The accuracies ranged from 0.29 to $-5.80 \%$ and recoveries between 92.73 and $101.97 \%$. Plasma samples and extracted supernatants were stable for 60 days at $-20^{\circ} \mathrm{C}$. A significant decrease of lycopene, $\beta$-carotene and retinol concentrations in plasma from exposed individuals compared to non-exposed individuals $(p<0.05)$ was observed. The method is simple, reproducible, precise, accurate and sensitive, and can be routinely utilized in clinical laboratories.

Keywords: retinol, $\alpha$-tocopherol, lycopene, $\beta$-carotene, HPLC, liquid-liquid extraction

\footnotetext{
*e-mail: solange.garcia@ufrgs.br
} 


\section{Introduction}

Epidemiological studies have shown that high intakes of carotenoids and vitamins $\mathrm{A}$ and $\mathrm{E}$ are associated with a lower risk to develop several chronic diseases. ${ }^{1-4}$ Several biological activities have been described for these compounds ${ }^{2}$ and the protective effects elicited by these substances may be in most cases a result of their antioxidant properties. ${ }^{5}$ Among these compounds, lycopene, $\beta$-carotene, retinol and $\alpha$-tocopherol are major components of the exogenous non-enzymatic antioxidant defense system, thus acting against peroxidation. .,7-9 $^{\text {. }}$

High-performance liquid chromatographic (HPLC) methods are considered the best choice for the determination of lipid-soluble vitamins. The first method developed for the quantification of these vitamins was described in $1973^{10}$ and up to now several studies have reported new methods for the quantification of these compounds with the use of various mobile phases, ${ }^{1,3-6,11,12-15}$ the adoption of chromatographic columns with either normal $^{15,16}$ or reverse phases, ${ }^{3,4,6,11,17-21}$ and also different detectors, such as Vis, UV (DAD), 1,3-6,11,12-15,17-20,22-25 fluorescence (FLD), 4,6,15,18,19,22,24,25 and electrochemical (ECD) detectors. ${ }^{18,20,21,24,26}$ FLD is more sensitive than $\mathrm{UV}$, and is generally used in the quantification of tocopherols, ${ }^{4,15,19,22,24,25}$ and less frequently to quantify retinoids. . $22,25^{2}$

Many studies have indicated that it is necessary to use a gradient elution for the complete chromatographic separation of vitamins ${ }^{1,3,11,15,19,20,22,25}$ and other works have described an isocratic elution. ${ }^{4-6,12-14,16,17,21,23}$ Gradient elution involves a substantially longer chromatographic time, compared to the isocratic method, and also requires a rebalance of the HPLC system after injections. ${ }^{12}$ So, methods that use isocratic elution are faster and less laborious.

Several procedures for sample extraction have been reported for vitamins, some of them based on protein precipitation using an organic solvent such as ethanol, methanol, isopropanol or acetonitrile, followed by liquid-liquid extraction and/or evaporation of the organic solvent under nitrogen stream and posterior reconstitution, ${ }^{1,3-5,11-13,16,17,19-24,26}$ but these methods are normally very time-consuming. Extraction reagents include $n$-hexane, petroleum ether, dichloromethane-methanol, chloroform, ethyl acetate and $n$-butanol ${ }^{1,3-6,11-13,16,17,19-26}$ with the addition of antioxidants such as butylated hydroxytoluene $(\mathrm{BHT})^{4,6,13,16,19-23}$ or ascorbic acid ${ }^{5}$ to avoid oxidation of lipidsoluble vitamins. Therefore, extraction methods without many steps for the samples treatment would offer a great advantage in the analysis of hydrophobic vitamins.
In this work, a fast method using HPLC with Vis/ fluorescence detection and isocratic elution was developed in order to simultaneously quantify plasma lycopene, $\beta$-carotene, retinol and $\alpha$-tocopherol levels with a simple and rapid extraction procedure based on a single liquid-liquid extraction method. Moreover, stability tests were carried out using plasma samples and extracted supernatants previously stored at $-20{ }^{\circ} \mathrm{C}$.

\section{Experimental}

\section{Chemicals and reagents}

Lycopene, $\beta$-carotene, retinol, $\alpha$-tocopherol, BHT and ammonium acetate were purchased from Sigma-Aldrich (St. Louis, MO, USA). HPLC grade acetonitrile, dichloromethane, dioxane, ethanol, methanol, $n$-butanol and triethylamine were purchased from Tedia Company (Fairfield, USA).

Instrumentation and chromatographic conditions

The HPLC system, purchased from Shimadzu (Kyoto, Japan), consisted of a quaternary pump LC-20AT and degasser DGU-20A5, an automatic injector with cooler SIL20-ACHT, a column oven CTO-20A, UV/Vis detector SPD-20AV, fluorescence detector RF-10XL and system controller CBM-20A. Chromatographic peaks and data were processed using LC Solution Software ${ }^{\circledR}$, version 1.25.

Vitamins were separated by isocratic elution with a mixture of acetonitrile:dioxane:methanol solution:triethylamine $(81.7: 15: 3: 0.3, \mathrm{v} / \mathrm{v})$ as mobile phase. Methanol solution consisted of $0.1 \mathrm{~mol} \mathrm{~L}^{-1}$ ammonium acetate dissolved in methanol. The flow rate was set to $1.6 \mathrm{~mL} \mathrm{~min}{ }^{-1}$, using a Shim-pack CLC-ODS $(150 \mathrm{~mm} \times 4 \mathrm{~mm}, 5 \mu \mathrm{m})$ column connected to a guard column ODS and kept under thermostatization at $20^{\circ} \mathrm{C}$.

The eluate absorbance was monitored at $450 \mathrm{~nm}$ to quantify lycopene and $\beta$-carotene, whereas fluorescence readings at two different excitation and emission wavelengths were monitored to quantify retinol and $\alpha$-tocopherol. Retinol was detected using excitation and emission wavelengths of 340 and $520 \mathrm{~nm}$, respectively. These settings were maintained from the time of injection until $5 \mathrm{~min}$. At $5 \mathrm{~min}$, the excitation wavelength was changed to $298 \mathrm{~nm}$ and the emission wavelength changed to $328 \mathrm{~nm}$ in order to quantify $\alpha$-tocopherol. These conditions were maintained up to $15 \mathrm{~min}$ and returned to the initial excitation and emission wavelengths until the end of chromatographic run at $25 \mathrm{~min}$. Both Vis and fluorescence detectors were arranged in series. 


\section{Standard solutions and standard curve preparation}

All standards were protected from light and manipulated using amber microtubes. Vitamin stock solutions were prepared as follows: lycopene and $\beta$-carotene solutions (each one at $1.8 \mathrm{mmol} \mathrm{L}^{-1}$ ) were prepared in dichlorometane, retinol $\left(3.5 \mathrm{mmol} \mathrm{L}^{-1}\right)$ was dissolved in ethanol, and $\alpha$-tocopherol $\left(0.2 \mathrm{~mol} \mathrm{~L}{ }^{-1}\right)$ was prepared in ethanol: $n$-butanol $(50: 50, \mathrm{v} / \mathrm{v})$. BHT at $5 \mathrm{mg} \mathrm{mL}^{-1}$ was added to all solvents. The stock solutions were transferred into amber microtubes and stored at $-80{ }^{\circ} \mathrm{C}$. Their actual concentrations were spectrophotometrically confirmed (after dilution in ethanol) using their appropriated absorption coefficients. ${ }^{12}$

Intermediate standard solutions were separately prepared in the concentrations of $10 \mu \mathrm{mol} \mathrm{\textrm {L } ^ { - 1 }}$ for lycopene and $\beta$-carotene, $100 \mu \mathrm{mol} \mathrm{L}{ }^{-1}$ for retinol and $500 \mu \mathrm{mol} \mathrm{L}^{-1}$ for $\alpha$-tocopherol, and each one was diluted in ethanol: $n$-butanol (50:50, v/v) containing BHT $\left(5 \mathrm{mg} \mathrm{mL}^{-1}\right)$. For standard calibration curves, the intermediate standard solutions were diluted in ethanol: $n$-butanol $(50: 50, \mathrm{v} / \mathrm{v})$ containing BHT (5 mg mL $\mathrm{mL}^{-1}$ ) to obtain a mixture of five different concentrations of working standard solutions in the ranges of 0.25-8, 2-64, 0.025-0.8 and 0.025-0.8 $\mu \mathrm{mol} \mathrm{L} \mathrm{L}^{-1}$ for retinol, $\alpha$-tocopherol, lycopene and $\beta$-carotene, respectively. These solutions were daily prepared, protected from light and kept on ice during the procedure. For the preparation of a matrix-based standard curve, a fixed volume $(30 \mu \mathrm{L})$ of each diluted mixture of working standard solutions was spiked into $150 \mu \mathrm{L}$ of plasma pool, then $90 \mu \mathrm{L}$ aliquots of each spiked concentration were transferred into amber microtubes and the samples were further processed with ethanol: $n$-butanol solution (50:50, v/v) containing BHT $\left(5 \mathrm{mg} \mathrm{mL}^{-1}\right.$ ) for extraction, as described below. For plasma basal levels, a fixed volume $(30 \mu \mathrm{L})$ of ethanol: $n$-butanol solution (50:50, v/v) containing BHT (5 mg mL $\left.\mathrm{mL}^{-1}\right)$ was added to $150 \mu \mathrm{L}$ of plasma pool and processed.

\section{Sample procedure}

Venous blood samples from all volunteers were collected into $5 \mathrm{~mL}$ Vacutainer ${ }^{\circledR}$ tubes containing an edta (ethylenediaminetetraacetic acid) solution as anticoagulant and were maintained at $0-4{ }^{\circ} \mathrm{C}$ and protected from light until centrifugation. The blood samples were centrifuged at $1500 \times \mathrm{g}$ for $10 \mathrm{~min}$ in a refrigerated centrifuge $\left(4^{\circ} \mathrm{C}\right)$ and plasma was divided into $500 \mu \mathrm{L}$ aliquots and stored at $-80{ }^{\circ} \mathrm{C}$ until analysis.

The extraction procedure was carried out in duplicate and samples were kept on ice bath, in a room protected from direct light exposure. In an amber microtube, $90 \mu \mathrm{L}$ of plasma were mixed with $450 \mu \mathrm{L}$ ethanol: $n$-butanol solution (50:50, v/v) containing BHT $\left(5 \mathrm{mg} \mathrm{mL}^{-1}\right)$, vortex mixed for $10 \mathrm{~s}$, let stand for $5 \mathrm{~min}$ on ice and under light protection, and mixed again for $10 \mathrm{~s}$, followed by centrifugation at $2700 \times \mathrm{g}$ for $3 \mathrm{~min}$; $400 \mu \mathrm{L}$ of the clear supernatants were transferred to vials. Vials were capped and immediately placed in an autosampler maintained at $4{ }^{\circ} \mathrm{C}$. Then, $20 \mu \mathrm{L}$ of each sample were injected into the HPLC system for simultaneous quantification of vitamins.

\section{Assay validation}

Linearity, precision, accuracy, recovery and sensitivity

A linear relationship should be evaluated in the range of concentrations assayed in the analytical procedure. Linearity was determined by five standard curves at $0.025,0.1,0.2$, 0.4 and $0.8 \mu \mathrm{mol} \mathrm{L}^{-1}$ for both lycopene and $\beta$-carotene, 0.25 ,

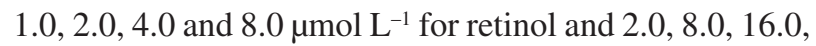
32.0 and $64.0 \mu \mathrm{mol} \mathrm{L} \mathrm{L}^{-1}$ for $\alpha$-tocopherol spiked in plasma. Plasma without spiked vitamins was considered the basal level, once lipid-soluble vitamins are ubiquitous in plasma samples and vitamin-free plasma cannot be obtained. The standard curves were prepared on five different days and the linear regression was calculated.

Intra- and inter-run precisions and accuracy of the method were evaluated on five separated days. Three standard concentrations $\left(0.025,0.1\right.$ and $0.8 \mu \mathrm{mol} \mathrm{L}^{-1}$ for lycopene and $\beta$-carotene, $0.25,1.0$ and $8.0 \mu \mathrm{mol} \mathrm{L^{-1 }}$ for retinol and 2.0, 8.0 and $32 \mu \mathrm{mol} \mathrm{L}{ }^{-1}$ for $\alpha$-tocopherol) were prepared in replicates and injected into HPLC. The intra- and inter-run precisions were expressed by means of coefficient of variation $(\mathrm{CV})$. Accuracy was calculated as percentage bias.

Recoveries of vitamins from the matrix were determined by spiking plasma samples with retinol $\left(0.25-8.0 \mu \mathrm{mol} \mathrm{L} \mathrm{L}^{-1}\right)$, $\alpha$-tocopherol (2.0-64 $\left.\mu \mathrm{mol} \mathrm{L} \mathrm{L}^{-1}\right)$, lycopene and $\beta$-carotene

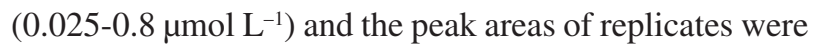
compared to those of standard solutions.

Sensitivity of the method was determined by limits of detection (LOD) and quantification (LOQ) using standard deviation of the response $(s)$ and the slope from the calibration curve $(b)$ plotted at analyte concentrations near the limits, according to ICH recommendations. ${ }^{27}$ The limits were calculated by following equations: $\mathrm{LOD}=3.3 \mathrm{~s} / \mathrm{b}$ and LOQ $=10 s / b$. The standard deviation of the response was calculated based on the standard deviation of the intersection of the line with the $y$-axis.

\section{Stability in plasma before and after extraction}

To perform the stability tests of lycopene, $\beta$-carotene, retinol and $\alpha$-tocopherol in plasma after storage at $-20{ }^{\circ} \mathrm{C}$, blood samples from four volunteers from the 
Federal University of Rio Grande do Sul were drawn into $5 \mathrm{~mL}$ Vacutainer ${ }^{\circledR}$ tubes containing edta, centrifuged at $4{ }^{\circ} \mathrm{C}$ and the plasma pool was separated into aliquots. One aliquot was analyzed at the day of collection in replicate by quantification in the HPLC system. The remaining plasma aliquots were stored at $-20^{\circ} \mathrm{C}$ and the stability was evaluated at 1, 10, 20,30, 60 and 90 days after collection of blood sample. Moreover, the remaining supernatant from the sample extraction procedure at the day of collection was separated in aliquots for storage at $-20^{\circ} \mathrm{C}$ and the stability was tested at 1, 10, 20,30,60 and 90 days after extraction. The peak areas obtained from these time intervals were compared to the aliquot extracted at the day of collection.

\section{Ruggedness}

The ruggedness of the method was tested in plasma samples by varying some chromatographic parameters, such as mobile phase composition, flow rate, temperature and analysts.

\section{Application}

Forty-five male industrial painters from the Rio Grande do Sul State (Brazil) and a corresponding control group of thirty men not exposed to paints, whose ages were $28.50 \pm 1.80$ and $28.70 \pm 1.80$ years (mean \pm standard deviation), respectively, were enrolled in this study. Plasma samples from the participants were collected in edta tubes and submitted to the analytical procedure previously described for the quantification of lipid-soluble vitamins, after methodological validation.

The study was approved by the Ethics Committee in Research of the Federal University of Santa Maria (UFSM) and informed consent was required for all participants (No. 23081.015931/2006-59).

\section{Statistical analyses}

All data obtained from the validation parameters and human plasma samples were analyzed using the software Statistica 6.0 for Windows and Mann-Whitney test was applied for independent samples. All results were expressed as mean \pm standard deviation. A value of $p<0.05$ was considered significant.

\section{Results and Discussion}

\section{Extraction of vitamins}

Several HPLC methods for the determination of carotenoids, retinol and $\alpha$-tocopherol in human serum or plasma have been reported. However, most of them require protein precipitation, liquid-liquid extraction, drying under nitrogen stream and sample reconstitution prior to

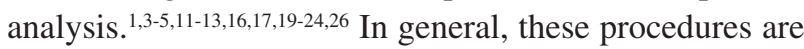
quite laborious and do not eliminate the risk of unwanted transformations such as isomerization, oxidation and formation of degradation products. ${ }^{25}$

Approximately $90 \%$ of the total plasmatic lipidsoluble vitamins in humans is associated with low-density lipoprotein and high-density lipoprotein fractions, so protein precipitation procedures with ethanol, methanol, isopropanol or acetonitrile, followed by extraction with organic solvents, have been currently used..$^{25}$ In our opinion, this procedure can be shortened by the use of organic solvents, such as a mixture of ethanol and $n$-butanol, which can perform lipid extraction by breaking up the lipoproteins.

Abahusain et al. ${ }^{17}$ have adopted a liquid-liquid extraction and posterior injection directly into HPLC for the quantification of retinol, $\alpha$-tocopherol and $\beta$-carotene but not for lycopene, which is an important non-enzymatic antioxidant in the body, whose determination provides important information of the antioxidant status. These authors obtained a prolonged extraction time of approximately $30 \mathrm{~min}$. Also, Taibi and Nicotra ${ }^{25}$ reported a simple and fast extraction procedure utilizing a solvent mixture, but the method allowed only the quantification of two lipid-soluble vitamins, retinol and $\alpha$-tocopherol. However, the majority of methods that enable the quantification of these lipid-soluble vitamins and carotenoids require many steps for their extraction from the sample matrix ${ }^{1,3-5,11-13,16,17,19-24,26}$ resulting in a much longer procedure. Recently, Thibeault et al. ${ }^{12}$ proposed a fast method for the quantification of 9 compounds (carotenoids, tocopherols and retinol) with a total run time of $15 \mathrm{~min}$, but the previous extraction procedure was approximately 40 min and included many steps, resulting in a long time of analysis (approximately $55 \mathrm{~min}$ ) and a laborious extraction procedure.

In this work, it is reported a simple and rapid sample preparation procedure (approximately $10 \mathrm{~min}$ ) in which five volumes of an ethanol: $n$-butanol solution (50:50, $\mathrm{v} / \mathrm{v})$ containing BHT (5 mg $\left.\mathrm{mL}^{-1}\right)$ were used to perform the extraction of retinol, $\alpha$-tocopherol, lycopene and $\beta$-carotene, consisting of a one-step extraction, followed by a direct injection of the extracted samples into the HPLC system and a total analysis time of approximately 33 min with a simultaneous detection of the four analytes. Therefore, this method allows the analysis of a large series of samples in a few minutes, which is important in epidemiological or clinical studies. 


\section{Chromatography}

The validated method described in this study adequately separates and quantifies four analytes (lycopene, $\beta$-carotene, retinol and $\alpha$-tocopherol) in a single run using reverse-phase chromatography, isocratic elution along with Vis and FLD detector. Typical chromatograms of a standard mixture and plasma samples are shown in Figure 1A and Figure 1B, respectively. The retention times for retinol, $\alpha$-tocopherol, lycopene and $\beta$-carotene were $2.3,8.5,11.4$ and $21.3 \mathrm{~min}$, respectively, and the total run time was $25 \mathrm{~min}$. Unfortunately, all of the peaks obtained after injection of the biological samples into the HPLC system could not be properly identified because of a lack of pure standards. However, even though it was not possible to identify these peaks, it was possible to separate these unknown peaks from the identified peaks, so that they do not interfere with peaks obtained from the analytes. Therefore, the suitable resolution found for the chromatographic peaks obtained by our method contributes to the method specificity.

Furthermore, triethylamine and ammonium acetate have been regarded as important reagents necessary to increase the yield of carotenoids, particularly lycopene and $\beta$-carotene. ${ }^{12,28}$ In view of this findings, it was used a mobile phase with $3 \mathrm{mmol} \mathrm{L}^{-1}$ of ammonium acetate and it was conducted tests to evaluate the efficiencies of two different concentrations of triethylamine $(0.03$ and $0.3 \%, \mathrm{v} / \mathrm{v})$. The results showed that the higher concentration of triethylamine tested $(0.3 \%, \mathrm{v} / \mathrm{v})$ was more appropriate for the quantification of lycopene and $\beta$-carotene due to an improvement of peak resolution and an increase in peak area (data not shown).

\section{Validation}

Linearity, precision, accuracy, recovery and sensitivity

Linearity and reproducibility were evaluated by linear regression. The equations obtained by the least square

(A)

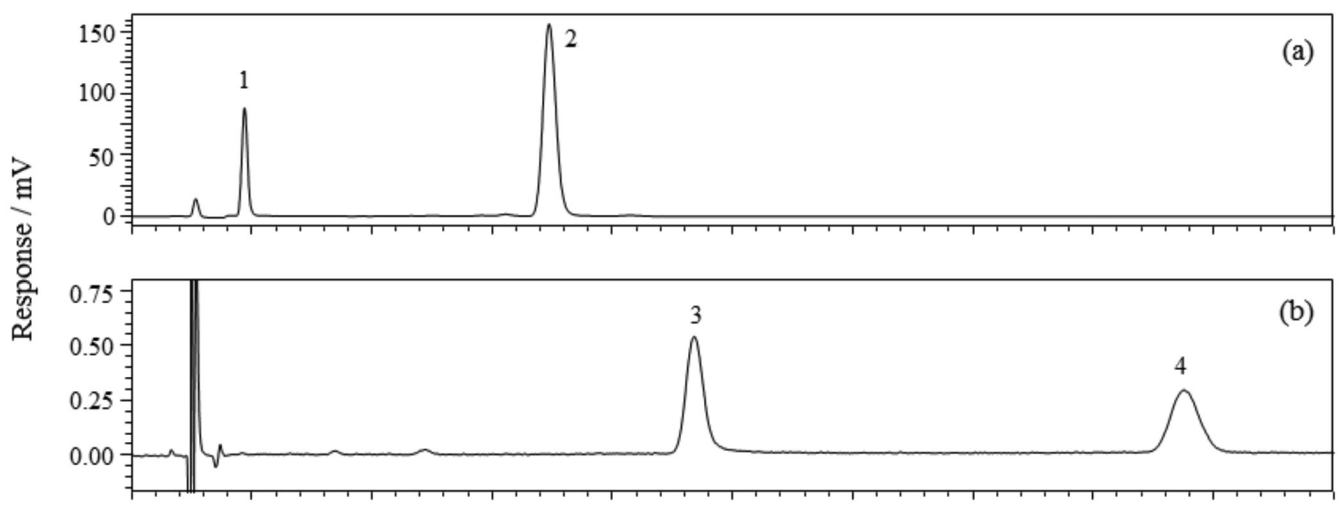

(B)

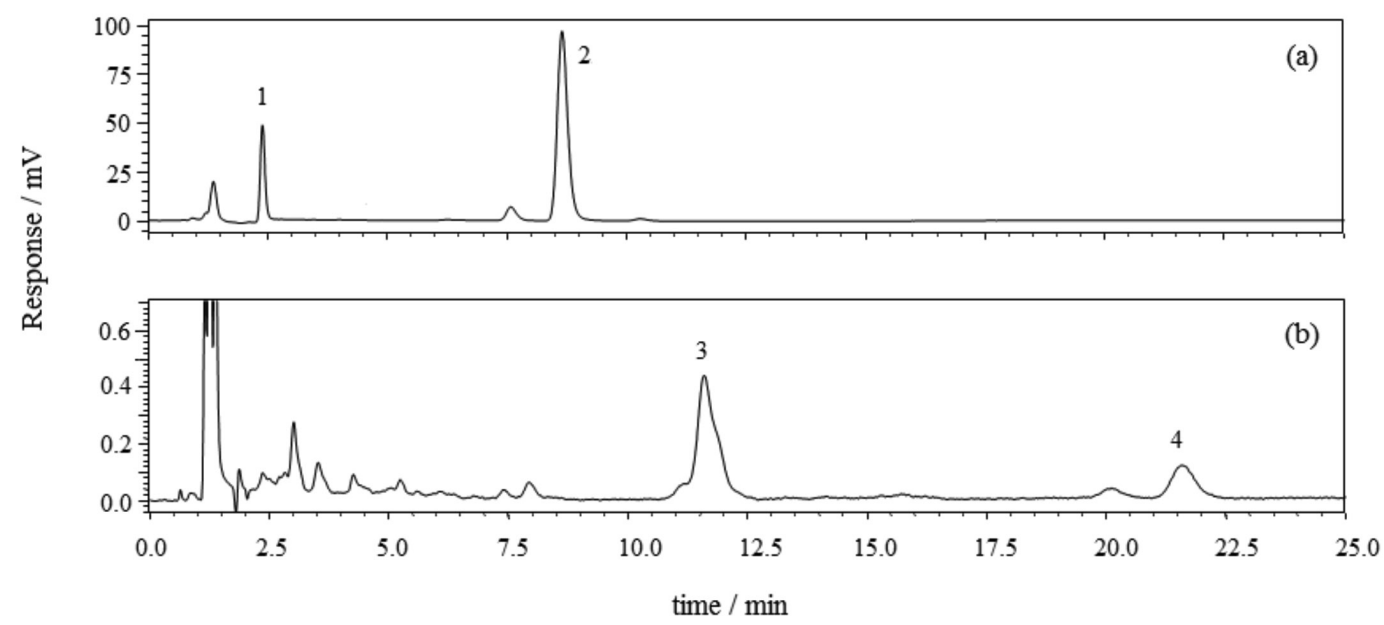

Figure 1. (A) Typical chromatograms obtained from injection of a mixture of vitamin standards prepared in ethanol: $n$-butanol solution (50:50, v/v) containing BHT (5 mg mL $\mathrm{mL}^{-1}$ ) into the HPLC system; (B) typical chromatograms obtained from injection of unspiked human plasma pool (basal samples) into the chromatographer; (a) fluorometric detector programmed to monitor readings at $\lambda \mathrm{ex}=340 \mathrm{~nm}$ and $\lambda \mathrm{em}=520 \mathrm{~nm}$ for retinol, and $\lambda$ ex $=280 \mathrm{~nm}$ and $\lambda$ em $=328 \mathrm{~nm}$ for $\alpha$-tocopherol, in which (1) retinol and (2) $\alpha$-tocopherol, and (b) Vis detector programmed to monitor absorbances at $\lambda=450 \mathrm{~nm}$, in which (3) Lycopene and (4) $\beta$-carotene. 
regression and the correlation coefficients ( $r$ ) are presented in Table 1. Analytical curves (i.e., peak areas from each concentration of spiked plasma against peak areas from retinol, $\alpha$-tocopherol, lycopene and $\beta$-carotene standard solutions) showed excellent linearity and parallelism with the following correlation coefficients: 0.998, 0.999, 0.999 and 0.997 for lycopene, $\beta$-carotene, retinol and $\alpha$-tocopherol, respectively. Figure 2 depicts the standard curves in the linearity range, in which the average areas and standard deviation for each concentration are represented.

LOD and LOQ (determined by $3.3 s / b$ and $10 s / b$, respectively) were sufficiently low to measure the lowest tested concentrations of lycopene and $\beta$-carotene. The sensitivity of each parameter was similar to previous studies from Lee $e t$ al. ${ }^{4}$ and Thibeault et al.,${ }^{12}$ in which methods for the simultaneous quantification of retinol, $\alpha$-tocopherol and carotenoids were described, and the LOD and LOQ values were satisfactory to quantify plasmatic lipid-soluble vitamins in samples from a clinical analysis routine. LOD and LOQ are presented in Table 1.

The intra- and inter-run precisions (expressed in percentage by the variation coefficient, $\mathrm{CV}$ in \%) and the accuracy (as percentage of bias) were based on peak area ratios and are represented in Table 2.

Plasma samples were spiked with known amounts of retinol, $\alpha$-tocopherol, lycopene and $\beta$-carotene to calculate the recoveries of each vitamin after the extraction procedure. Data from the recoveries are shown in Table 2. These results were considered satisfactory, once they

Table 1. Equations obtained by the least squares regression, correlation coefficients (r) for standard calibration and standard spiked curves and sensitivity parameters for each analyte

\begin{tabular}{lcccccc}
\hline Analyte & Standard calibration curve & $\mathrm{r}$ & Standard spiked curve & $\mathrm{r}$ & $\mathrm{LOD} /(\mu \mathrm{mol} \mathrm{L}-1)$ & $\mathrm{LOQ}^{-1}(\mu \mathrm{mol} \mathrm{L}-1)$ \\
\hline Lycopene & $y=59364 x-252.33$ & 0.999 & $y=55211 x-599.81$ & 0.997 & 0.003 & 0.009 \\
$\beta$-Carotene & $y=63703 x-15.91$ & 0.999 & $y=63586 x-248.12$ & 0.999 & 0.005 & 0.015 \\
Retinol & $y=372736 x-8562.8$ & 1 & $y=405787 x-40224$ & 0.999 & 0.024 & 0.073 \\
$\alpha$-Tocopherol & $y=178761 x-22874$ & 0.999 & $y=205172 x-171711$ & 0.999 & 0.276 & 0.838 \\
\hline
\end{tabular}
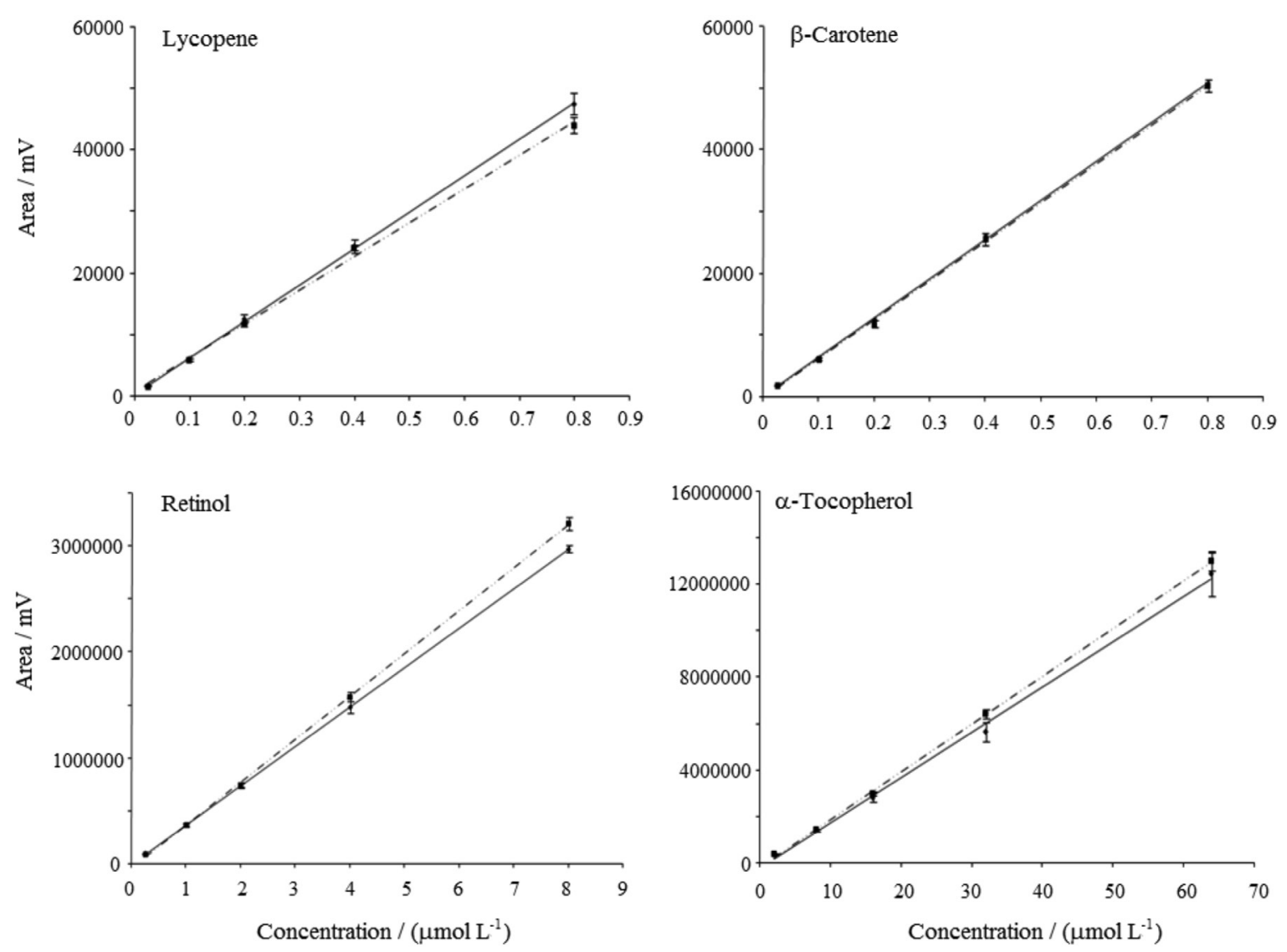

Figure 2. Standard calibration (-) and standard spiked $(-\cdots-)$ curves $(n=5)$ with average areas and standard deviation for each concentration. 
Table 2 Results from the validation parameters (precision, accuracy and recovery) of plasma samples spiked with vitamin standards

\begin{tabular}{lccccc}
\hline Analyte & $\begin{array}{c}\text { Concentration / } \\
\left(\mu \mathrm{mol} \mathrm{L}^{-1}\right)\end{array}$ & $\begin{array}{c}\text { Intra-run } \\
\text { precision } \pm \mathrm{SD} / \%\end{array}$ & $\begin{array}{c}\text { Inter-run } \\
\text { precision } \pm \mathrm{SD} / \%\end{array}$ & $\begin{array}{c}\text { Accuracy } \pm \text { SD / } \\
\% \text { bias }\end{array}$ & \multicolumn{2}{c}{ Recovery \pm SD / } \\
$\%$
\end{tabular}

SD: standard deviation.

ranged within the accepted values for bioanalytical methods (around $\pm 15 \%) .{ }^{29}$

\section{Ruggedness}

Method ruggedness was considered satisfactory when analyses were carried out under different chromatographic conditions, such as mobile phase composition, and when different analysts performed the analyses. Furthermore, the temperature was ranged from 18 to $23^{\circ} \mathrm{C}$ and the flow rate from 1.5 to $1.7 \mathrm{~mL} \mathrm{~min}^{-1}$, also providing satisfactory results. These data indicated that this method could be suitably used for the quantification of retinol, $\alpha$-tocopherol, lycopene and $\beta$-carotene in plasma samples without interference from minor analytical changes.

\section{Stability}

Some authors reported that plasma samples under storage at $-70{ }^{\circ} \mathrm{C}$ are stable for at least 12 months ${ }^{5}$ or 4 years. ${ }^{30}$ However, few studies have assessed the stability of retinol, $\alpha$-tocopherol, lycopene and $\beta$-carotene in plasma samples and in extracted supernatants when stored at $-20{ }^{\circ} \mathrm{C} .{ }^{11,17}$ Abahusain et al. ${ }^{17}$ conducted a stability study for retinol, $\alpha$-tocopherol and $\beta$-carotene, but not for lycopene. Moreover, Su et al. ${ }^{11}$ showed that the stability of untreated plasma and extracted samples was limited to $72 \mathrm{~h}$.

In this work, it is reported data of a stability study from plasma samples (Figure 3A) and extracted supernatants (Figure 3B) stored at $-20{ }^{\circ} \mathrm{C}$ for 90 days. It is possible to observe that no significant losses of lycopene, retinol, $\alpha$-tocopherol and $\beta$-carotene levels were found until the second month (60 days) of storage for plasma and extracted materials, all of which remained within the accepted range, which should be around $\pm 10 \% .{ }^{29}$ In the third month, only retinol was stable in the plasma and extracted material, whereas the other vitamins showed significant losses. Consequently, our data indicate that plasma samples
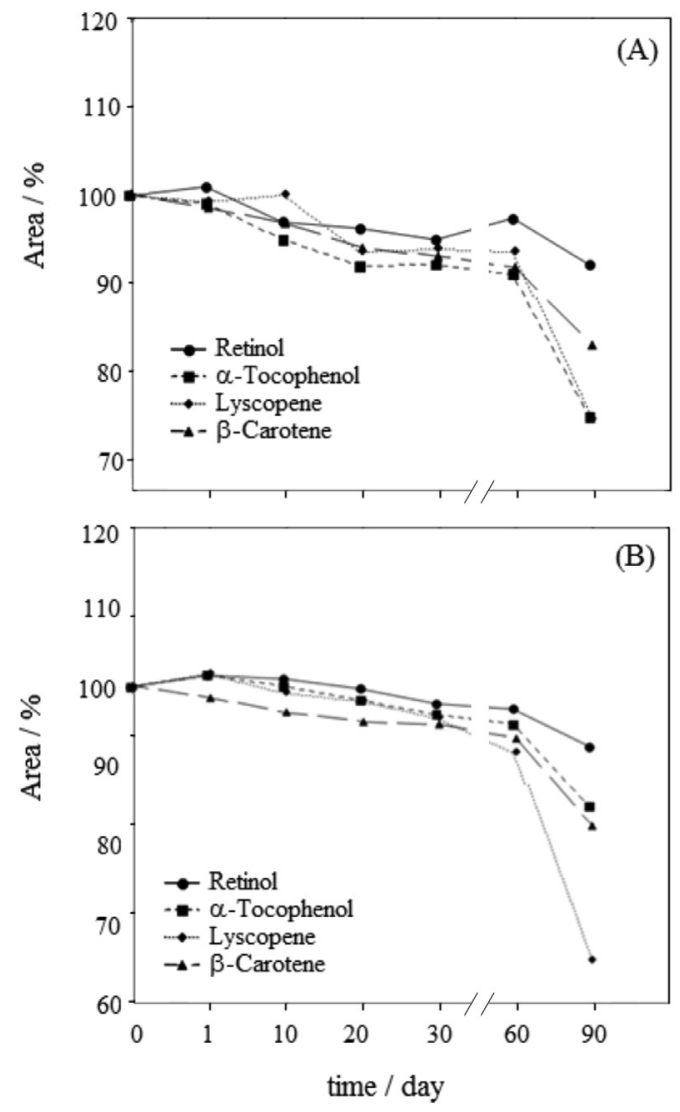

Figure 3. (A) Stability tests conducted in plasma samples collected with edta stored at $-20^{\circ} \mathrm{C}$ for each analyte, in which " 0 " in $x$-axis represents the collection day and other numbers range until the $90^{\text {th }}$ day after collection; (B) stability tests for each analyte conducted in plasma samples collected with edta after liquid-liquid extraction with ethanol: $n$-butanol solution $(50: 50, \mathrm{v} / \mathrm{v})$ containing BHT $\left(5 \mathrm{mg} \mathrm{mL}^{-1}\right)$ followed by storage at $-20^{\circ} \mathrm{C}$ from the collection day until 90 days. 
with edta could be stored at $-20^{\circ} \mathrm{C}$ until two months with reliability prior to analysis.

\section{Application}

After the determination of the validation parameters previously described, the method was applied to biological samples obtained from human volunteers in order to determine the levels of plasma retinol, $\alpha$-tocopherol, lycopene and $\beta$-carotene, as possible protective factors in a group of 45 painters working in an industry located in the Rio Grande do Sul State and a corresponding control group of 30 men, all non-exposed to paints (Table 3 ). The results indicate that exposed individuals present significantly lower lycopene, $\beta$-carotene and retinol concentrations when compared to controls $(p<0.01)$, despite the fact that all vitamins ranged within reference values in subjects from both groups of study. ${ }^{31}$

Table 3 Plasma lycopene, retinol, $\alpha$-tocopherol and $\beta$-carotene levels from the groups of study $(\mathrm{n}=75)$

\begin{tabular}{lcc}
\hline $\begin{array}{l}\text { Analyte / } \\
\left(\mu \mathrm{mol} \mathrm{L} \mathrm{L}^{-1}\right)\end{array}$ & $\begin{array}{c}\text { Non-exposed group } \\
(\mathrm{n}=30)\end{array}$ & $\begin{array}{c}\text { Exposed group } \\
(\mathrm{n}=45)\end{array}$ \\
\hline Lycopene & $0.68 \pm 0.18$ & $0.55 \pm 0.24^{\mathrm{a}}$ \\
$\beta$-Carotene & $0.52 \pm 0.34$ & $0.36 \pm 0.20^{\mathrm{a}}$ \\
Retinol & $2.30 \pm 0.40$ & $1.99 \pm 0.38^{\mathrm{a}}$ \\
$\alpha$-Tocopherol & $25.60 \pm 6.25$ & $23.24 \pm 6.18$ \\
\hline
\end{tabular}

The results are expressed as mean $\pm \mathrm{SD}$ (standard deviation); ${ }^{\mathrm{a}} p<0.01$.

\section{Conclusions}

An analytical method for the quantification of plasma retinol, $\alpha$-tocopherol, lycopene and $\beta$-carotene levels was optimized and validated. The method showed excellent linearity, precision, accuracy and recoveries for all vitamins of interest.

The advantage of the method is the simultaneous extraction and analysis of four lipid-soluble vitamins from human plasma with a simple and fast liquid-liquid extraction procedure. Besides, another advantage is that only a few microliters of plasma $(90 \mu \mathrm{L})$ are necessary to perform the analyses. The stability study showed that there was no significant decrease in the concentration of the four analytes in plasma and in the extracted supernatants when kept stored at $-20{ }^{\circ} \mathrm{C}$ for 60 days. In summary, this method was developed to be used for quantitative analysis and offers the possibility to determine the levels of these non-enzymatic vitamins in plasma samples from epidemiological studies with a large number of subjects, considering that the plasma or extracted supernatants can be stored at $-20{ }^{\circ} \mathrm{C}$ for two months without analyte loss. Moreover, to our knowledge this is the first report that painters possess decreased levels of the non-enzymatic vitamins analyzed in plasma with this methodology, future studies are still necessary to further investigate the antioxidant status in this group of workers occupationally exposed to paints.

\section{Acknowledgements}

The authors would like to thank Coordenação de Aperfeiçoamento de Pessoal de Nível Superior (CAPES/ DAAD PROBRAL 352/10, for a grant to S. C. Garcia) and Conselho Nacional de Desenvolvimento Científico e Tecnológico (CNPq/MCT, No. 479613/2009-5, for a grant to P. H. Saldiva) for the financial support. M. F. Charão is the recipient of CAPES/REUNI MSc fellowship. $\mathrm{S}$. C. Garcia is the recipient of CNPq research fellowship.

\section{References}

1. Ortega, H.; Coperías, J. L.; Castilla, P.; Gómez-Coronado, D.; Lasunción, M. A.; J. Chromatogr., B: Anal. Technol. Biomed. Life Sci. 2004, 803, 249.

2. Olmedilla, B.; Granado, F.; Southon, S.; Wright, A. J. A.; Blanco, I.; Gil-Martinez, E.; van den Berg, H.; Corridan, B.; Roussel, A. M.; Chopra, M.; Thurnham, D. I.; Br. J. Nutr. 2001, $85,227$.

3. Steghens, J. P.; van Kappel, A. L.; Riboli, E.; Collombel, C.; J. Chromatogr., B: Anal. Technol. Biomed. Life Sci. 1997, 694, 71.

4. Lee, B. L.; New, A. L.; Ong, C.N.; Clin. Chem. 2003, 49, 2056.

5. Talwar, D.; Ha, T. K. K.; Cooney, J.; Brownlee, C.; St JO’Reilly, D.; Clin. Chim. Acta 1998, 270, 85.

6. Semeraro, A.; Altieri, I.; Patriarca, M.; Menditto, A.; J. Chromatogr., B: Anal. Technol. Biomed. Life Sci. 2009, $877,1209$.

7. Stahl, W.; Sies, H.; Biochim. Biophys Acta 2005, 1740, 101.

8. Shi, J.; Kakuda, Y.; Yeunq, D.; BioFactors 2004, 21, 203.

9. Yuan, J. M.; Gao, Y. T.; Ong, C. N.; Ross, R. K.; Yu, M. C.; J. Natl. Cancer Inst. 2006, 98, 482.

10. Vecchi, M.; Vesely, J.; Oesterhelt, G.; J. Chromatogr., A. 1973, $83,447$.

11. Su, Q.; Rowley, K. G.; O’Dea, K.; J. Chromatogr., B: Anal. Technol. Biomed. Life Sci. 1999, 729, 191.

12. Thibeault, D.; Su, H.; MacNamara, E.; Schipper, H. M.; J. Chromatogr., B: Anal. Technol. Biomed. Life Sci. 2009, 877, 1077.

13. Vertzoni, M. V.; Reppas, C.; Archontaki, H. A.; J. Chromatogr., B: Anal. Technol. Biomed. Life Sci. 2005, 819, 149.

14. Xu, F.; Yuan, Q. P.; Dong, H. R.; J. Chromatogr., B: Anal. Technol. Biomed. Life Sci. 2006, 838, 44. 
15. Casal, S.; Macedo, B.; Oliveira, M. B. P. P.; J. Chromatogr., B: Anal. Technol. Biomed. Life Sci. 2001, 763, 1.

16. Boonsiri, P.; Pooart, J.; Tangrassameeprasert, R.; Hongsprabhas, P.; Asia Pac. J. Clin. Nutr. 2007, 16, 47.

17. Abahusain, M. A.; Wright, J.; Dickerson, J. W. T.; El-Hazmi, M. A.; Enein, H. Y. A.; Biomed. Chromatogr. 1998, 12, 89.

18. Aust, O.; Sies, H.; Stahl, W.; Polidori, M. C.; J. Chromatogr., A. 2001, 936, 83.

19. Thomas, J. B.; Kline, M. C.; Gill, L. M.; Yen, J. H.; Duewer, D. L.; Sniegoski, L. T.; Sharpless, K. E.; Clin. Chim. Acta 2001, 305, 141.

20. MacCrehan, W. A.; Schönberger, E.; Clin. Chem. 1987, 33, 1585.

21. Finckh, B.; Kontush, A.; Commentz, J.; Hübner, C.; Burdelsk, M.; Kohlschütter, A.; Anal. Biochem. 1995, 232, 210.

22. Siluk, D.; Oliveira, R. V.; Esther-Rodriguez-Rosas, M.; Ling, S.; Bos, A.; Ferrucci, L.; Wainer, I. W.; J. Pharm. Biomed. Anal. 2007, 44, 1001.

23. Tzouganaki, Z. D.; Atta-Politou, J.; Koupparis, M. A.; Anal. Chim. Acta 2002, 467, 115.

24. Rupérez, F. J.; Mach, M.; Barbas, C.; J. Chromatogr., B: Anal. Technol. Biomed. Life Sci. 2004, 800, 225.
25. Taibi, G.; Nicotra, C. M. A; J. Chromatogr., B: Anal. Technol. Biomed. Life Sci. 2002, 780, 261.

26. Wang, L. H.; Wang, J. F.; J. Pharm. Biomed. Anal. 2001, 25, 785.

27. ICH - International Conference on Harmonisation, Q2B, Validation of Analytical Procedures: Methodology, Geneva, 2005, p. 1-9.

28. Craft, N. E.; Methods Enzimol. 1992, 213, 185

29. Causon, R.; J. Chromatogr., B: Anal. Technol. Biomed. Life Sci. 1997, 689, 175.

30. Comstock, G. W.; Norkus, E. P.; Hoffman, S. C.; Xu, M. W.; Helzlsouer, K. J.; Cancer Epidemiol. Biomarkers Prev. 1995, $4,505$.

31. Burtis, C.; Ashwood, E.; Eward, R. In Fundamentos de Química Clínica, $5^{\text {th }}$ ed.; Guanabara Koogan: Rio de Janeiro, Brasil, 1998.

Submitted: August 24, 2011

Published online: July 10, 2012

FAPESP has sponsored the publication of this article. 